\title{
Shifts in microbial community composition in tannery-contaminated soil in response to increased gamma radiation
}

\author{
Mohammad A. A. Al-Najjar ${ }^{1}$ Majed M. Albokari ${ }^{2}$
}

Received: 27 March 2019 / Accepted: 9 September 2019/Published online: 23 December 2019

(C) The Author(s) 2019

\begin{abstract}
Purpose Contaminated sites from man-made activities such as old-fashioned tanneries are inhabited by virulent microorganisms that exhibit more resistance against extreme and toxic environmental conditions. We investigated the effect of different Gamma radiation doses on microbial community composition in the sediment of an old-fashioned tannery.

Methods Seven samples collected from the contaminated sites received different gamma radiation doses $(I=0.0, I I=5, I I I=10$, $\mathrm{VI}=15, \mathrm{~V}=20, \mathrm{VI}=25$, and $\mathrm{VII}=30 \mathrm{kGy}$ ) as an acute exposure. The shift in microbial community structure was assessed using the high throughput 454 pyrosequencing. Variations in diversity, richness, and the shift in operational taxonomic units (OTUs) were investigated using statistical analysis.

Result Our results showed that the control sample (I) had the highest diversity, richness, and OTUs when compared with the irradiated samples. Species of Halocella, Parasporobacterium, and Anaerosporobacter had the highest relative abundance at the highest radiation dose of $30 \mathrm{kGy}$. Members of the Firmicutes also increased by $20 \%$ at the highest radiation dose when compared with the control sample $(0.0 \mathrm{kGy})$. Representatives of Synergistetes decreased by $25 \%$ while Bacteroidetes retained a steady distribution across the range of gamma radiation intensities.

Conclusion This study provides information about potential "radioresistant" and/or "radiotolerant" microbial species that are adapted to elevated level of chemical toxicity such as $\mathrm{Cr}$ and $\mathrm{Sr}$ in tannery. These species can be of a high biotechnological and environmental importance.
\end{abstract}

Keywords Tannery wastewater $\cdot$ Bacterial diversity · Gamma rays $\cdot 454$ pyrosequencing $\cdot$ Radioresistant $\cdot$ Firmicutes · Synergistetes

\section{Introduction}

Gamma radiation is widely used in many applied sciences, especially those fields targeting material improvement, soil and food preservation including sterilization and quality assurance for consumables. Gamma radiation is a favorable tool for studying soil properties and elimination of soil organisms

Electronic supplementary material The online version of this article (https://doi.org/10.1007/s13213-019-01541-z) contains supplementary material, which is available to authorized users.

Majed M. Albokari

mbokari@kacst.edu.sa

1 Faculty of Pharmacy, Applied Science Private University, Amman, Jordan

2 Nuclear Science Research Institute (NSRI), King Abdulaziz City for Science and Technology (KACST), Riyadh, Saudi Arabia
(Gebremikael et al. 2015; McNamara et al. 2003). Selecting the suitable irradiation dose for a soil is also affected by factors like moisture content, hydrocarbon content, soil type, and biological diversity (Nunan et al. 2017; VanMensel et al. 2017). Shifts in the microbial and biological profile of irradiated soil could be dependent on soil physicochemical properties (i.e., moisture, $\mathrm{pH}$ ) (Gebremikael et al. 2015). In addition, variations in microbial community in an irradiated soil sample could be determined by several factors, such as light, exposure time, organic matter, and biological processes, i.e., fermentation and DNA repair (Brown et al. 2015; Gebremikael et al. 2015; McNamara et al. 2003). Recent reviews (Jung et al. 2017; Pavlopoulou et al. 2016) reported several potential mechanisms for microbial radiation resistance including reactive oxygen species (ROS) detoxification systems, enzymatic antioxidant processes, and DNA repair systems. However, gamma radiation causes cytoplasmic water radiolysis resulting in protein oxidation, which leads to the survival of 
bacteria in soil or sediment (Brown et al. 2015). Consequently, this redox conditions can inhibit or enhance the microbial activity and it quantifiably changes the microbial profile when compared with the indigenous available microbes (Schaller et al. 2011) and this is reflected by the presence of higher energy yield generated from electron donors and acceptors (Brown et al. 2015). In addition, the ability to use redundant genetic information and cell lysis to repair DNA damage after irradiation has been reported (Billi et al. 2000) for Chroococcidiopsis strains isolated from desert and hypersaline environments. Therefore, the isolation, identification, and characterization of microorganisms that can survive in irradiated or extreme and toxic soil has become of particular interest for scientists working in environmental biotechnology and bioremediation of contaminated sites, to investigate the level of radiation resistance and the mechanisms of resistance of those microorganisms.

Different range of gamma radiation doses can sterilize and eliminate the majority of organisms in soil. For example, in most soils, fungi, actinomycetes, and invertebrates can be eliminated with a maximum dose of $10 \mathrm{kGy}$ while $20 \mathrm{kGy}$ can kill the majority of existing bacteria (McNamara et al. 2003). At the Hanford Site, Washington State, a contaminated radioactive site, Deinococcus radiodurans strains were isolated from samples contaminated with $>20 \mu \mathrm{Ci}$ of ${ }^{137} \mathrm{Cs} \mathrm{g} \mathrm{g}^{-1}$ (Fredrickson et al. 2004) along with other isolates from samples contaminated with $>10 \mu \mathrm{Ci}$ of ${ }^{137} \mathrm{Cs} \mathrm{g}^{-1}$ (Fredrickson et al. 2004) reported that Gram-positive bacteria, i.e., Arthrobacter, and phyla with high $\mathrm{G}+\mathrm{C}$ content, i.e., Rhodococcus, could survive the extreme physical and chemical stress associated with radioactive waste. In practice, $10 \mathrm{kGy}$ of gamma radiation was enough to induce changes in the microbial community from garden clay (El-Sayed and Ghanem 2009) which was dependent on the type of bacteria and soil properties.

Combination of organic material content and moisture content affects irradiation dose and microbial community structure. In a comparative study, different irradiation doses using a gamma facility $\left({ }^{60} \mathrm{Co}\right.$ source) were applied on two soil samples collected from the Sonoran Desert and Louisiana forest (Rainey et al. 2005). Interestingly, some bacteria were isolated from the desert soil after irradiation up to $30 \mathrm{kGy}$, mainly from three genera: Deinococcus, Geodermatophilus, and Hymenobacter, while there were no isolates from the forest soil sample irradiated above $13 \mathrm{kGy}$. These ionizing radiationresistant bacteria isolated from the desert soil might enhance the further development and evolution of other DNA repair systems that protect cells against external stressors (Rainey et al. 2005). Similarly, Deinococcus deserti was isolated from the Sahara Desert in Morocco and Tunisia and it survived as colony-forming bacteria on agar plates after receiving $15 \mathrm{kGy}$ radiation dose (de Groot et al. 2005).

Most known gamma radioresistant species belong to the Archaea, with a small proportion belonging to bacteria such as Deinococcus. For example, three hyperthermophilic archaeal species have shown radiation resistance. Thermococcus gammatolerans and Thermococcus radiotolerans were isolated from a deep-sea hydrothermal vent chimney of the Guaymas Basin and their growth was observed at $30 \mathrm{kGy}$ (Jolivet et al. 2003, 2004) while Thermococcus marinus was isolated from a sample obtained from an active chimney wall from the Snakepit hydrothermal site on the Mid-Atlantic Ridge, after exposure to $20 \mathrm{kGy}$ (Jolivet et al. 2004). A range of bacterial species belonging to Deinococcus and Geodermatophilus genera have shown signs of activity and growth at up to $30 \mathrm{kGy}$ (Rainey et al. 2005) while members of the genus Hymenobacter could not grow after exposure to radiation exceeding $25 \mathrm{kGy}$ (Rainey et al. 2005; Zhang et al. 2007). Rubrobacter is another important genus, with three species (Rubrobacter radiotolerans, Rubrobacter xylanophilus, and Rubrobacter taiwanensisi) that survived at $18 \mathrm{kGy}$ with variable heat tolerance (Chen et al. 2004). Species in the genus Deinococcus are not only resistant to gamma radiation but also to ultraviolet radiation, such as Deinococcus saxicola, Deinococcus frigens, and Deinococcus marmoris (Hirsch et al. 2004). Chroococcidiopsis and Methylobacterium genera contain species with radioresistance up to $15 \mathrm{kGy}$ (Billi et al. 2000; Rainey et al. 2005) while other genera such as Kineococcus and Kocuria contain species that have shown growth at lower doses (i.e., $<10 \mathrm{kGy}$ ) and Arthrobacter sp. survived at a maximum of up to $3 \mathrm{kGy}$ (Rainey et al. 2005).

The present study focused on the effect of gamma radiation on the indigenous microbial communities of contaminated sites and consequently the redistribution of major genera and phyla of subsurface soil samples collected from a tannerycontaminated site using high throughput 454 pyrosequencing. We aimed to understand which groups of microorganisms can withstand the effect of radiation, and to investigate their potential biotechnological applications.

\section{Materials and methods}

\section{Sample collection}

Samples were collected from a remote area located near the second industrial city to the south of Riyadh, Saudi Arabia $\left(24^{\circ} 27^{\prime} 07.72^{\prime \prime} \mathrm{N}\right.$ and $\left.46^{\circ} 53^{\prime} 04.79^{\prime \prime} \mathrm{E}\right)$, where several old hangers hosting old-fashioned tannery activities are ongoing. Tannery effluents are being discharged to an arid site close to the hangers via sewage tankers. Twenty random samples around the site were collected in appropriate sterilized bottles. The soil was solid enough to allow gentle handling and mixing of the samples to improve homogeneity. The bulk was divided into seven subsamples and around $2.0 \mathrm{~g}$ of each sample was exposed to different irradiation doses using an in- 
house gamma facility (GC-220E, Nordion Inc., Ottawa, ON, Canada) at a dose rate of $4 \mathrm{kGy} / \mathrm{h}$, where ${ }^{60} \mathrm{Co}$ activity was $23,766 \mathrm{Ci}$, as follows: $\mathrm{I}=0.0 \mathrm{kGy}$ (control), $\mathrm{II}=5 \mathrm{kGy}, \mathrm{III}=$ $10 \mathrm{kGy}, \mathrm{IV}=15 \mathrm{kGy}, \mathrm{V}=20 \mathrm{kGy}, \mathrm{VI}=25 \mathrm{kGy}$, and $\mathrm{VII}=$ $30 \mathrm{kGy}$. The seven samples were then transferred and kept for 30 days in the dark at room temperature prior to DNA extraction to avoid contamination of samples by degraded DNA fragments caused by irradiation.

\section{Chemical analysis of the soil}

Three soil samples were collected randomly from the tannerycontaminated site, in addition to a sample from a reference site ( $\sim 12 \mathrm{~km}$ away from the tannery site). Soil samples were dried thoroughly, then sieved through a $2-\mathrm{mm}$ sieve. From each sieved soil, $0.50 \mathrm{~g}$ was digested in a mixture of $5 \mathrm{ml}$ of $\mathrm{HNO}_{3}, 2 \mathrm{ml}$ of $\mathrm{HF}$, and $2 \mathrm{ml}$ of $\mathrm{HCl}$. Trace elements were measured by inductively coupled plasma mass spectrometry (ICP-MS), whereas a recovery of $98-100 \%$ was achieved using certified reference soil of Internal Atomic Energy Agency soil IAEA-SOIL-7.

\section{DNA extraction, PCR amplification, and pyrosequencing}

DNA from each soil sample $(1.0 \mathrm{~g})$ was extracted for bacterial identification and analysis. Genomic DNA was extracted using a PowerSoil DNA Isolation Kit (MO BIO Laboratories Inc., Solana Beach, CA, USA); a Nanodrop 1000 spectrophotometer (Thermo Fisher Scientific, Wilmington, DE, USA) was used to quantify the DNA extracted. PCR, purification, and sequencing of genomic DNA (gDNA) were then conducted using Mr. DNA Lab (Molecular Research LP, Shallowater, TX, USA). PCR amplicon sequencing for 454 pyrosequencing was performed using (bTEFAP®) according to Dowd et al. (2008a, b). The technology of 454 pyrosequencing, which is performed using a Roche 454 FLX titanium instrument, is a high throughput DNA sequencing method that uses a single strand of DNA with a length of 400-500 bp. All DNA samples were adjusted to $100 \mathrm{ng} / \mu \mathrm{l}$, and $100 \mathrm{ng}(1 \mu \mathrm{l})$ aliquots of each sample were used for a $50-\mu \mathrm{l}$ PCR reaction. Forward and reverse $16 \mathrm{~S}$ universal eubacterial primers 515F (GTGCCAGCMGCCGCGGT AA) and 806R (GGACTACHVGGGTWTCTAAT) (Caporaso et al. 2011) were used for a single-step 30 cycle PCR. The PCR amplification was accomplished using a HotStar Taq plus Master Mix Kit (Qiagen, Valencia, CA, USA) under the following conditions, $94{ }^{\circ} \mathrm{C}$ for $30 \mathrm{~min}$, followed by 28 cycles of $94{ }^{\circ} \mathrm{C}$ for $30 \mathrm{~s}, 53{ }^{\circ} \mathrm{C}$ for $40 \mathrm{~s}$ and $72{ }^{\circ} \mathrm{C}$ for $1 \mathrm{~min}$, and then a final elongation step at $72{ }^{\circ} \mathrm{C}$ for $5 \mathrm{~min}$. All amplicon products from different samples were mixed in equal concentrations and purified using Agencourt Ampure beads (Agencourt Bioscience Corporation, Beverly, MA, USA), then subjected to PCR.

\section{Microbial sequences analysis}

The sequence data was processed using a proprietary analysis pipeline owned by Molecular Research Lab (www.mrdnalab. com, MR DNA, Shallowater, TX). The following sequences were removed; barcode sequences and primers shorter than $200 \mathrm{bp}$, sequences with ambiguous base calls and sequences with homopolymer runs exceeding $6 \mathrm{bp}$. Finally, chimeras were removed after denoising sequences.

After the removal of singleton sequences, operational taxonomic units (OTUs) were defined and clustered at 97\% similarity. Taxonomic classification of OTUs was undertaken using BLASTn against a curated GreenGenes/ RDP/NCBI-derived database (DeSantis et al. 2006) and compiled into each taxonomic level. A package of different statistical analyses including XLstat, NCSS 2007, "R," and NCSS 2010 were utilized for hierarchical clustering, heat map analysis, and the "indval" calculation, respectively. The overall phylogenetic distance among communities was estimated using Fast UniFrac (Hamady et al. 2009) of the relative abundances and visualized using principal coordinate analysis (PCoA) (Hamady et al. 2009; Lozupone et al. 2007). To compare OTUs among samples, shared OTUs were identified using XOR analysis (CL community program; Chunlab Inc. Seocho-gu, Seoul, Republic of Korea) (Cha et al. 2014; Hollinshead et al. 2014).

\section{Results}

\section{Chemical analysis}

The chemical analysis of the soil in the tannery site showed pronounced increase in the concentration of specific elements compared to a reference site $(12 \mathrm{~km}$ away from the tannery site, Table 1). For example, $\mathrm{Cr}, \mathrm{Sr}$, and $\mathrm{Zn}$ concentrations in the tannery soil were respectively $\sim 6$ times, 2 times, and 1.5 times higher than the same elements in the reference soil. The concentrations of other elements tested (in Table 1) in the tannery soil were less than those of the reference soil.

\section{Diversity and composition of soil prokaryotes}

After stringent quality sequence curation, 23,297 sequences were parsed. A total of 18,550 sequences identified as bacteria and archaea, at $97 \%$ similarity, were used for the final analyses and the average number of reads per sample was 2650 (Table 2), The rarefaction curve was sufficient to reflect a satisfactory coverage of bacterial and archaeal richness (Fig. 1). All samples showed high diversity, reflected by the Shannon index, while it was the highest for sample I (4.90) and the lowest for samples VI and VII (4.49). The sample 
Table 1 The chemical composition of the soil sample within the tannery-contaminated site (triplicate) compared to a reference site (12 $\mathrm{km}$ away from the tannery site)

\begin{tabular}{|c|c|c|c|c|}
\hline & \multicolumn{2}{|l|}{ Reference soil } & \multicolumn{2}{|c|}{ Tannery-contaminated site } \\
\hline & ppm (mg/kg) & $\pm \mathrm{SD}$ & ppm (mg/kg) & $\pm \mathrm{SD}$ \\
\hline $\mathrm{Li}$ & 9.040 & 0.002 & 7.470 & 0.001 \\
\hline $\mathrm{Na}$ & $1.750 \times 10^{3}$ & 0.002 & $4.687 \times 10^{3}$ & 0.001 \\
\hline $\mathrm{Mg}$ & $6.930 \times 10^{3}$ & 0.001 & $3.882 \times 10^{3}$ & 0.002 \\
\hline K & $3.760 \times 10^{3}$ & 0.002 & $3.090 \times 10^{3}$ & 0.001 \\
\hline $\mathrm{Ca}$ & $211.000 \times 10^{3}$ & 0.001 & $126.200 \times 10^{3}$ & 0.001 \\
\hline $\mathrm{Cr}$ & 56.000 & 0.001 & 310.500 & 0.001 \\
\hline $\mathrm{Mn}$ & 190.000 & 0.001 & 118.250 & 0.000 \\
\hline $\mathrm{Fe}$ & $10.000 \times 10^{3}$ & 0.001 & $5.837 \times 10^{3}$ & 0.001 \\
\hline Co & 35.700 & 0.001 & 4.075 & 0.009 \\
\hline $\mathrm{Ni}$ & 18.400 & 0.001 & 9.728 & 0.002 \\
\hline $\mathrm{Cu}$ & 9.590 & 0.002 & 6.950 & 0.001 \\
\hline $\mathrm{Zn}$ & 25.700 & 0.002 & 38.525 & 0.001 \\
\hline $\mathrm{Rb}$ & 13.200 & 0.001 & 10.108 & 0.001 \\
\hline $\mathrm{Sr}$ & 165.000 & 0.001 & 328.250 & 0.001 \\
\hline Mo & 0.433 & 0.002 & 0.244 & 0.008 \\
\hline $\mathrm{Cd}$ & 0.098 & 0.013 & 0.134 & 0.007 \\
\hline $\mathrm{Ba}$ & 141.000 & 0.001 & 120.075 & 0.001 \\
\hline $\mathrm{Pb}$ & 6.960 & 0.001 & 5.500 & 0.001 \\
\hline $\mathrm{U}$ & 1.050 & 0.001 & 1.002 & 0.001 \\
\hline
\end{tabular}

exposed to treatment I recorded the highest Chao1 index (740), indicating that it had the richest microbial (bacteria and archaea) community, while the lowest was for treatment VII (Table 2),

UniFrac distance-based Jackknife clustering (Fig. 2) of the whole community (bacterial and archaeal communities) associated with the seven soil samples, I-VII, showed that there were three combined clusters, I/II, III/IV, V/VI, and a standalone cluster, VII.

A dual hierarchal dendrogram (Fig. 2) was constructed to provide a visual overview combining a heatmap for predominant genera and connection lines as clusters with more similar genera, based on matching similarity. Sample VII formed a cluster separate from that of samples I-VI, indicating a significant difference between the two clusters. Heatmap analysis and RDP classifiers revealed as many as 11 diverse genera that were present at $>5 \%$ among the seven samples, including Halocella, Anaerophaga, Aminobacterium, Virgibacillus, Clostridium, Thermus, Thermovirga, Anaerosporobacter, Parasporobacterium, Petrimonas, and Symbiobacterium (Figs. 3 and 5). Halocella, Parasporobacterium, and Anaerosporobacter were at their highest proportions in sample VII, with the highest radiation dose (30 kGy), when compared with their presence in the rest of the samples (I-VI, 0.0 $25 \mathrm{kGy}$ ).

Overall, the most predominant phylum identified from subsurface soil of the tannery-contaminated site was Firmicutes, which comprised an average of $57 \%$ followed by Synergistetes and Bacteroidetes at around 17 and 13\%, respectively, of the microbial population. However, the proportion of Firmicutes was highest (66\%) at the highest gamma dose in sample VII (30 kGy), when compared with the control sample ( $0.0 \mathrm{kGy})$, while the opposite occurred for Synergistetes. The major phyla detected and their relative abundances are outlined in (Fig. 4). In addition, at the genus level (Fig. 5), sequence frequency for members belonging to genera Aminobacterium and Clostridium were the highest across all samples, with averages of $\sim 13$ and $\sim$ $11 \%$, respectively. Parasporobacterium and Petrimonasthe were the least abundant with averages of 2 and $\sim 3 \%$, respectively. Genus Thermus was detected in only two samples: V (20 kGy) and VI ( $25 \mathrm{kGy})$, with significant percentages of $\sim 8$ and $\sim 6 \%$, respectively. Proteobacteria and Deinococcus-Thermus phyla just exceeded the threshold of $5 \%$ in only two samples, IV $(15 \mathrm{kGy}) / \mathrm{V}(20 \mathrm{kGy})$ and V (20 kGy)/VI (25 kGy), with average proportions of 8 and $7 \%$, respectively, of the whole microbial community. These phyla were detected in other samples at other radiation doses but at proportions of $<5 \%$, which were then discounted by the analysis software.

\section{Discussion}

Extermophilic habitats such as encrusted soils (Chennu et al. 2015) and hypersaline coastal sediments harbor very interesting versions of microbial communities on a micrometer scale

Table 2 Number of sequences, operational taxonomic units (OTUs) at 97\% similarity matching and diversity indices

\begin{tabular}{|c|c|c|c|c|c|c|c|}
\hline Index & I (control) & II (5 kGy) & III (10 kGy) & IV (15 kGy) & V (20 kGy) & VI (25 kGy) & VII (30 kGy) \\
\hline No. of seq & 4714 & 2886 & 2849 & 2556 & 2260 & 2195 & 1090 \\
\hline Total OTUs & 2302 & 1608 & 1481 & 1323 & 1221 & 1174 & 592 \\
\hline No. archaea OTUs & 88 & 44 & 37 & 30 & 30 & 20 & 15 \\
\hline No. bacteria OTUs & 2214 & 1437 & 1578 & 1293 & 1154 & 1184 & 577 \\
\hline Chao1 - richness & 740 & 505 & 490 & 468 & 462 & 390 & 354 \\
\hline Shannon - diversity & 4.90 & 4.87 & 4.75 & 4.65 & 4.61 & 4.49 & 4.49 \\
\hline
\end{tabular}


Fig. 1 UniFrac distance-based Jackknife clustering shows differences among the seven soil samples based on the operational taxonomic unit (out) data

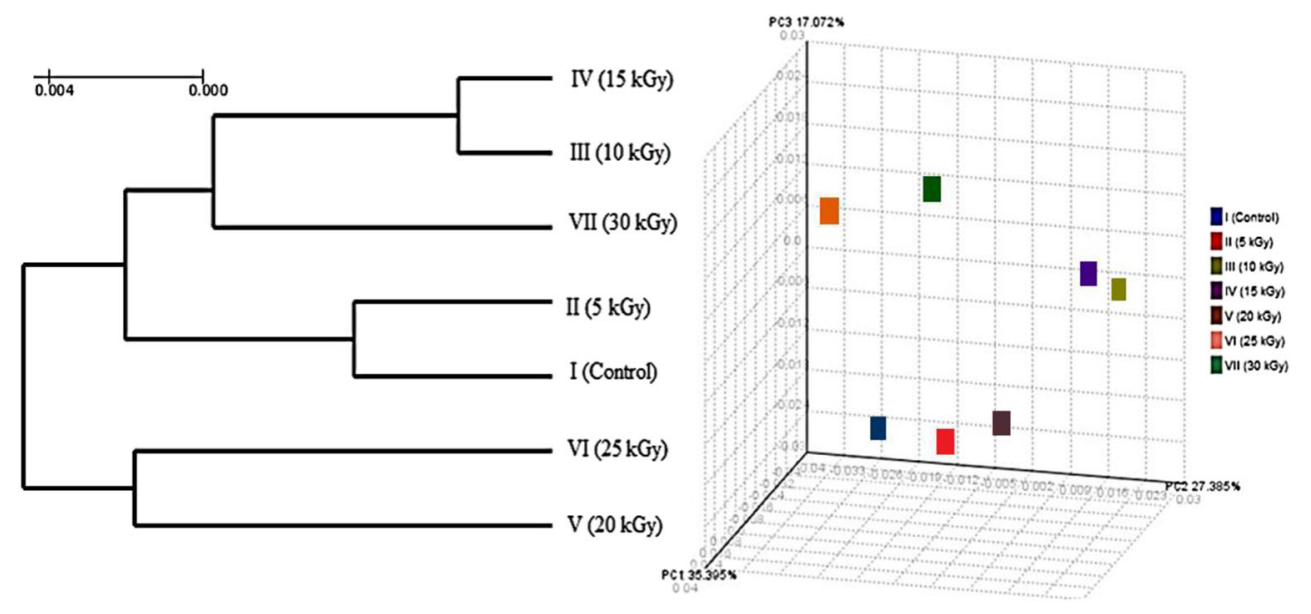

(Al-Najjar et al. 2014; Al-Thani et al. 2014). Toxic and polluted habitats of ecological systems, like tannery sites, contain unique microbial consortia (Albokari et al. 2018) and such microorganisms can tolerate those stresses and adapt to the current conditions. Previous work on this site (Albokari et al. 2018) showed the presence of both eukaryotic and prokaryotic microorganisms, including bacteria, archaea, and fungi within the surrounding toxic, polluted, and arid conditions. Our previous studies (Albokari et al. 2018) on the same site reported very high concentrations of $\mathrm{Cr}$, $\mathrm{Sr}$, and $\mathrm{Fe}$. In this study, gamma rays, as an external stress, were applied to the samples collected from the tannery-contaminated site to show the predominant microbial communities at different levels of radiation and to report any redistribution at the genus and phylum levels.

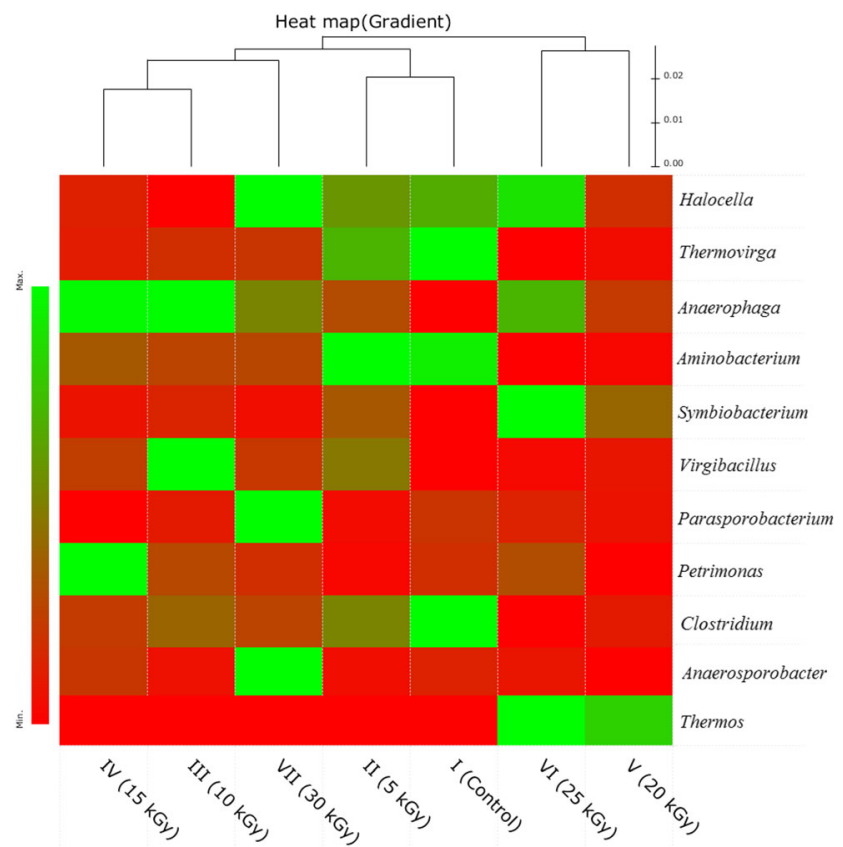

Fig. 2 Dual hierarchal dendrogram evaluation of the taxonomic classification data at the genus level

\section{Diversity and composition of soil prokaryotes}

Sediment, soil, and environmental samples (i.e., microbial mats) are very complex and heterogeneous systems when they are biologically and genetically evaluated. Studies on these samples are often non-repeatable, non-reproducible, and the microbial consortia differ from time to time based on the surrounding conditions and on the molecular tools assigned to the particular study (Delmont et al. 2011). The study of Delmont et al. (2011) reported that extraction methods do not provide a uniform and unbiased subsample of metagenomic DNA and resulted in different distribution of species. In Table 2, the control sample (sample I), which received $0.0 \mathrm{kGy}$, showed the highest diversity (Shannon) and richness (Chao1) indices and double the number of OTUs when compared with the irradiated samples (samples II-VII); this was expected as gamma irradiation kills soil organisms (Chen et al. 2004; ElSayed and Ghanem 2009; Hamdi et al. 2015; Song and Kuai 2017). The relationships between microbial communities in the different irradiated samples, as shown in (Fig. 2), support the impact of gamma radiation on the microbial community by restructuring of the indigenous community profile in treatment I (control, $0.0 \mathrm{kGy}$ ) and construction of three clusters combining treatment I/treatment II, treatment III/treatment IV, and treatment V/treatment VI; treatment VII was alone as it was very distinguished and different from the others.

We calculated the Indicator Value (IndVal) using the R software (ver 3.6.0) to indicate the species that can be used to gather information about the different radiation treatments (see the Supplementary Information file). Our analysis showed that with applying the different radiation treatments, the number of the indicator species decreased (taking the 0.7 as threshold), except for treatments IV and $\mathrm{V}$, where the number of indicator species increased. For example, the IndVal for treatment VI suggests that the two species Halococcus thailandensis and Sporosarcina sp. are the indicator for this treatment, while Acetivibrio sp. and Sporosarcina quimarina are the indicators for treatment VII (Supplementary Information). 


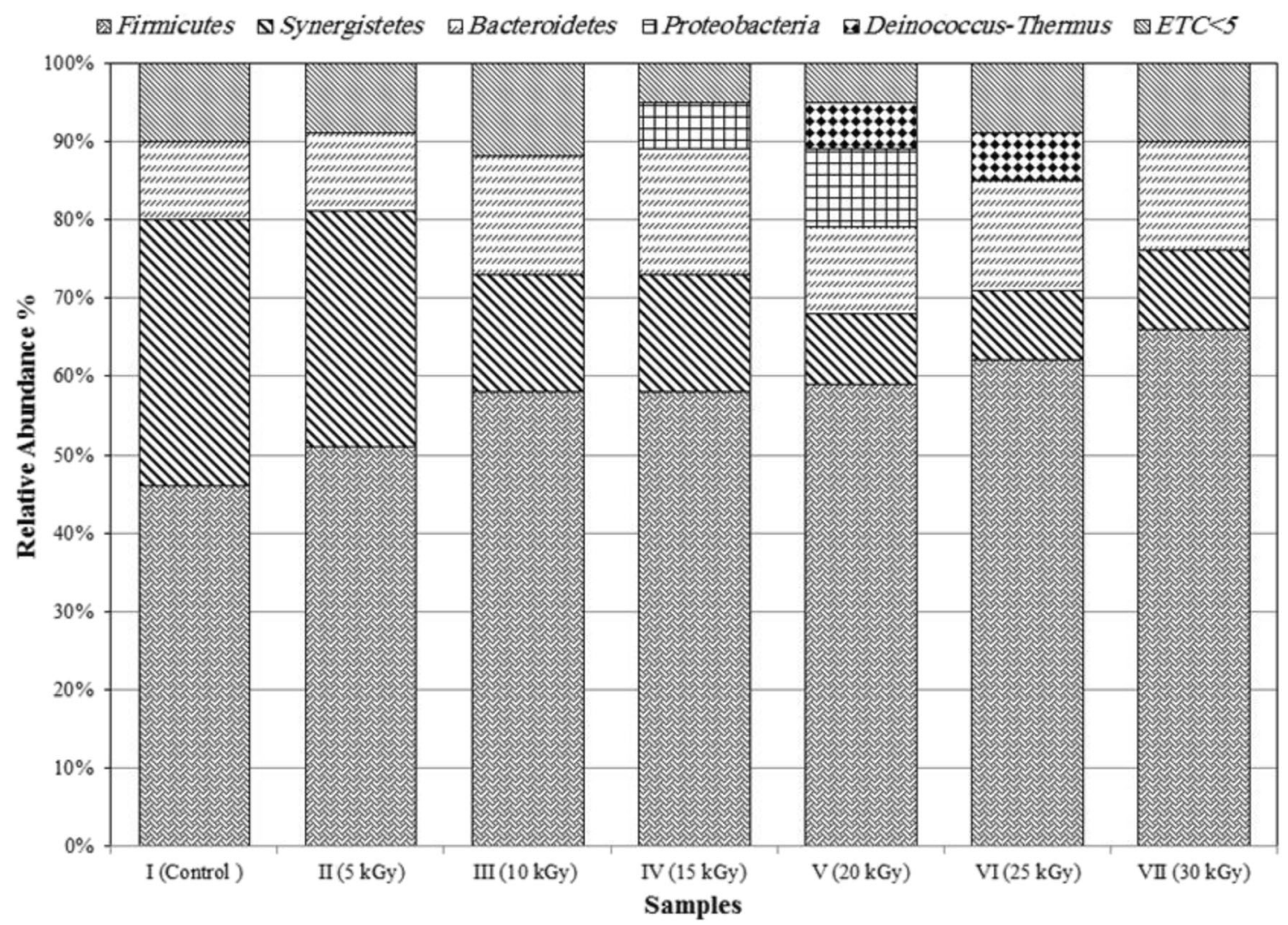

Fig. 3 Relative abundance of phyla across the irradiated tannery soil samples

The dominance of certain bacterial species indicates that these species had some form of radiation resistance. For example, Halocella species are halophiles and usually they were isolated from hypersaline lakes (Jiang et al. 2006) and saline environments. Moreover, species and genera of spore-forming bacteria such as Parasporobacterium and Anaerosporobacter (Jeong et al. 2007; Mechichi et al. 1999) could resist and survive high radiation doses, such as the $30 \mathrm{kGy}$ as in the present study, because of the unique formation of spores. Two other distinguished genera, Symbiobacterium and Thermus, survived at 20 and $25 \mathrm{kGy}$ and were dramatically affected by the maximum radiation dose in the present study, which was $30 \mathrm{kGy}$. Generally, Thermus species are very well known for their adaptation to high temperature and are very sensitive to ionizing radiation and desiccation (Omelchenko et al. 2005); this is why they might have perished in sample VII that received $30 \mathrm{kGy}$. However, in a recent comprehensive review (Ranawat and Rawat 2017) on the mechanisms of thermophiles to evade radiation resistance, it was reported that thermophilic radiation-resistant microbes can give deep insight into life in harsh environments by studying their adaptive mechanisms. The complex physiology of such microbes, coupling molecular tools, and biological approaches could help to understand the response of thermophiles to radiation.

Symbiobacterium species like Symbiobacterium thermophilum and Symbiobacterium toebii are symbiotic thermophiles that depend on co-culture growth (Kim et al. 2011; Ueda et al. 2004). They managed to survive up to $25 \mathrm{kGy}$ and then started to perish when Thermus species could not resist the maximum radiation dose of $30 \mathrm{kGy}$.

In contrast, three major prominent genera, Aminobacterium, Clostridium, and Thermovirga, were present at $>5 \%$ in sample I (control, $0.0 \mathrm{kGy}$ ) and sample II (lowest radiation dose, $5.0 \mathrm{kGy}$ ) and then showed very low similar redistribution and resistance to gamma rays up to 30 kGy.

Commonly, Aminobacterium and Clostridium are not known to be extremophiles or radioresistant species but they are representatives of Firmicutes, which have been shown to have spore formation or fermentation processes helping them against external stressors. Therefore, their responses to ionizing radiation were expected. Aminobacterium species such as Aminobacterium colombiense, Aminobacterium mobile, and Aminobacterium thunnarium are normally present in the food industry wastewater (Hamdi et al. 2015), while Clostridium species inhabit worldwide soil (Poehlein et al. 2017) and the intestinal tract of both humans and animals. Thermovirga species are moderately thermophilic (Dahle and Birkeland 2006) and most thermophiles are sensitive to ionizing radiation. Therefore, their abundance was halved from that in sample I starting from sample III (10 kGy). Three abundant genera (Anaerophaga, Virgibacillus, and Petrimonas) did not show 


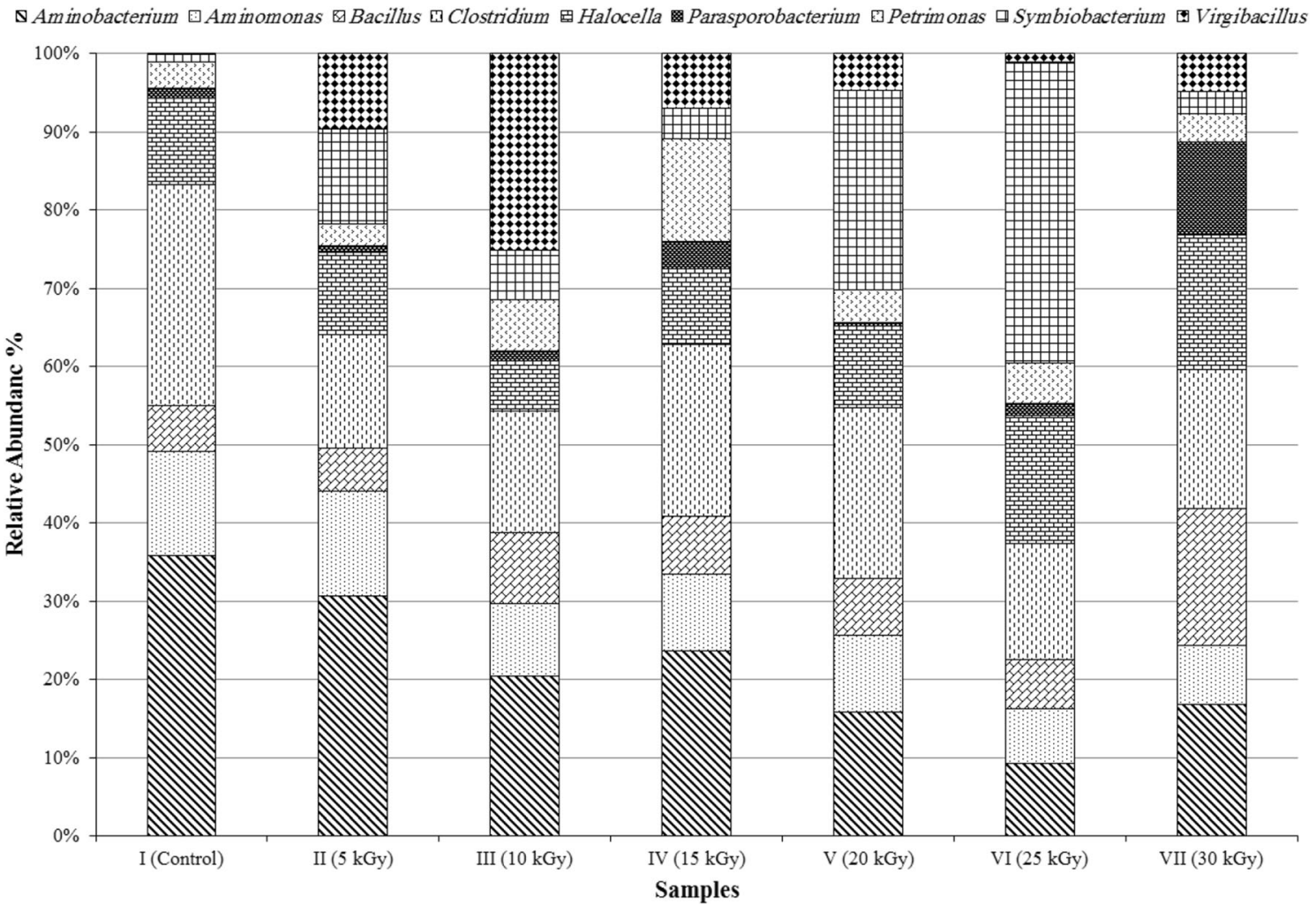

Fig. 4 Relative abundance of genera present at $>5 \%$ in the irradiated tannery soil samples

any clear trend in response to increasing the gamma radiation. Anaerophaga species are moderately thermohalophilic (Denger et al. 2002). Virgibacillus species vary between halophilic and halotolerant (Sánchez-Porro et al. 2014) and Petrimonas is mesophilic (Grabowski et al. 2005). In addition, the extraction, isolation, and detection of environmental microbes and species, especially from soil and sediment samples, are non-repeatable and non-reproducible processes and this might have resulted in the unclear trends of these three genera (Delmont et al. 2011). However, because of their salt (Virgibacillus) and heat (Anaerophaga and Petrimonas) tolerance, very low percentages $(1-4 \%)$ of these genera were detected in samples VI and VII.

Firmicutes and Synergistetes showed consistent trends and behavior across the samples, which probably reflected a marked functional diversity of some species within these two phyla. The former clearly increased while the latter decreased with increasing radiation doses from 0.0 up to $30 \mathrm{kGy}$. Firmicutes are very well known for their tolerance of harsh conditions and endospore formation (Filippidou et al. 2015; Wunderlin et al. 2013). Therefore, the community of Firmicutes species and representatives might increase their functional diversity to survive at higher doses of radiation ( 25 and $30 \mathrm{kGy}$ ) by increasing fermentation activity or spore formation, which is in agreement with the results of Brown et al. (2015). Synergistetes was mainly represented here by Aminobacterium and Thermovirga (Jumas-Bilak et al. 2009) and other members of its own genera (Grabowski et al. 2005), none of which are known as extremophilic or radioresistant. The Bacteroidetes phylum is distributed worldwide, especially in marine environments, and its bacterial species colonize all types of habitats including soil, ocean, freshwater, and the gastrointestinal tract of animals (Thomas et al. 2011). They are well known for degrading high molecular weight compounds and carbon compounds (Kabisch et al. 2014). Bacteroidetes showed almost steady distribution and behavior across all samples, with proportions varying from 10 to $16 \%$ and no effect of increasing radiation dose. This is in agreement with the results of El-Sayed and Ghanem (2009) where the physicochemical properties of polluted soil, especially with hydrocarbons, might impose a type of second-degree shelter or mechanism for indigenous species within the microbial community allowing them to be isolated and detected after exposure to gamma irradiation or external stressors. However, identification of representatives of this phylum at the higher radiation doses of 20-30 kGy, despite the fact that most of them are non-spore-forming and Gram-negative anaerobes, suggested that after exposure to gamma radiation some nonspore-forming species might be able to recover (Brown et al. 2015).

The response of Proteobacteria and Deinococcus-Thermus phyla to the radiation in our study is in agreement with Kabisch et al. (2014) where the tannery-contaminated site in this study was similar to the desert of Tataouine (Kabisch et al. 


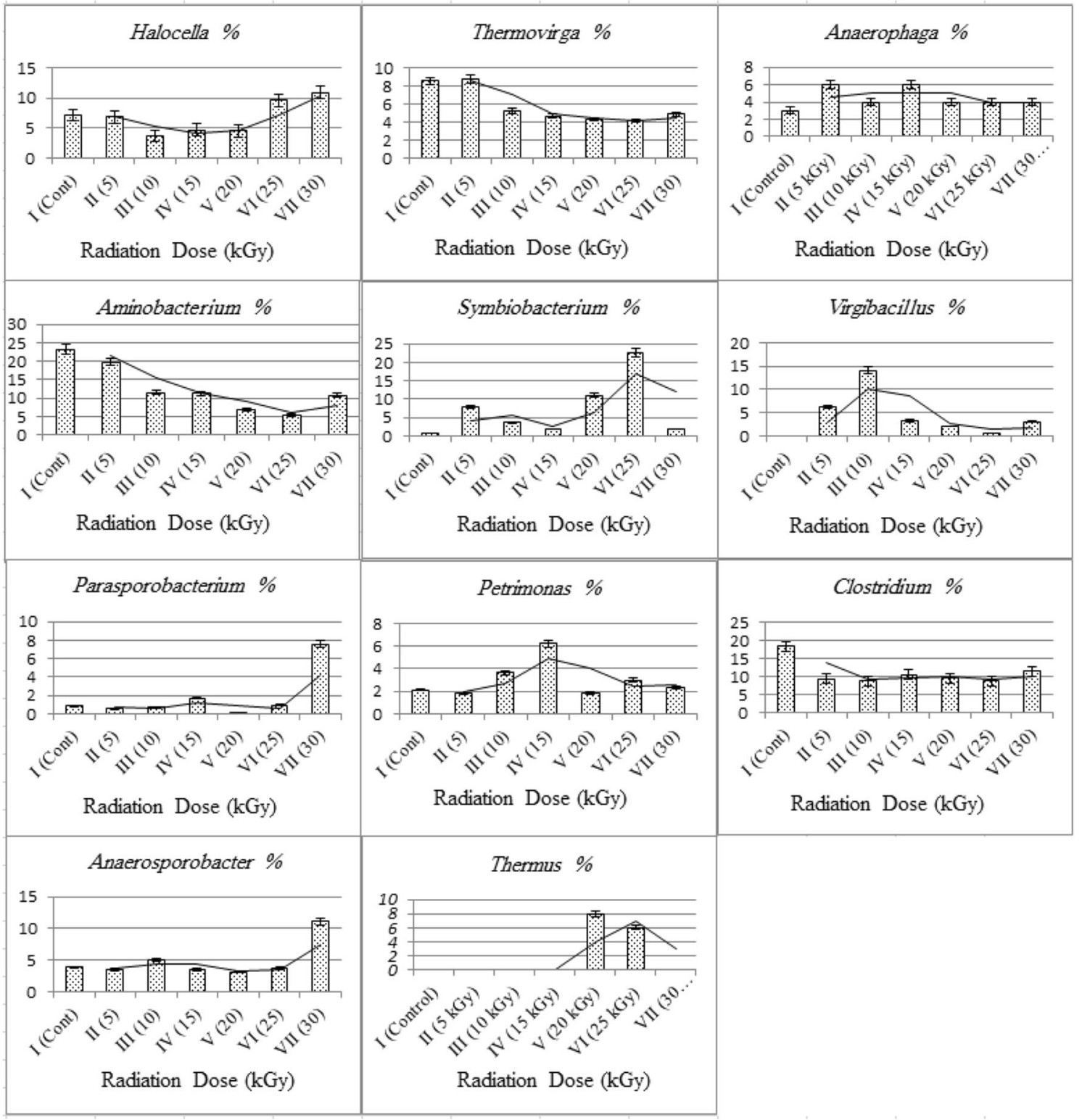

Fig. 5 Trends in abundance of specific genera among samples I-VII (0.0-30 kGy)

2014) in terms of aridity and high temperature, especially in the summer season. In the same study, Kabisch et al. (2014) tried to correlate a particular colonization ability of isolated strains from arid environments as a model of desiccation related to radiation tolerance. Nevertheless, phylum Deinococcus-Thermus includes species that are resistant (Chanal et al. 2006) to radiation (radioresistant and radiotolerant) and heat (thermophiles). Previously, species of the genus Thermus showed the same behavior, which indicated that they are thermophiles not radioresistant (Griffiths and Gupta 2007). Moreover, radiation-resistant species that belong to the genus Deinococcus like Deinococcus malanensis (Gabani and Singh 2013), Deinococcus rubrus (Zhu et al. 2017), Deinococcus actinosclerus (Srinivasan et al. 2017), Deinococcus radiotolerans (Cha et al. 2014), Deinococcus daejeonensis (Eun et al. 2016), Deinococcus deserti (de Groot et al. 2005), Deinococcus hohokamensis, Deinococcus navajonensis, Deinococcus hopiensis, Deinococcus apachensis, Deinococcus maricopensis, Deinococcus pimensis, Deinococcus yavapaiensis, Deinococcus papagonensis, Deinococcus sonorensis (Rainey et al. 2005), and Deinococcus radiodurans (Brooks and Murray 1981) were not detected and identified in this contaminated site using high throughput 454 pyrosequencing.

\section{Biotechnological significance of tannery prokaryotes}

The tannery soil showed the presence of important bacterial species with known biotechnological importance. Halocella sp. has strong capabilities to hydrolyze hydrocarbon 
compounds, as its genome contains 21 genes associated with the glycoside hydrolases (Heng et al. 2019). Halocella sp. produces important enzymes such as cellulase, hemicellulose, and amylase (Heng et al. 2019). Moreover, the genome of the Halocella strain SP3-1 comprises the presence of the putative bacteriocin-encoding genes (Heng et al. 2019). Bacteriocins are peptides produced by bacteria that inhibit or kill other microorganisms, making them potentially useful for the food and pharmaceutical industries (Heng et al. 2019). Anaerophaga sp. is known to produce an orange-red pigment which is similar to carotenoids (Denger et al. 2002). Cells of Anaerophaga have the ability to lower the surface tension of the medium because they produce a surface-active extracellular compound, which is heat-tolerant up to $70{ }^{\circ} \mathrm{C}$ (Denger et al. 2002). Virgibacillus sp. can produce three special types of proteinases, belonging to bacillopeptidase F-like enzymes exhibiting thermophilic and halotolerant characteristics with high stability at 30\% NaCl (Phrommao et al. 2011; SánchezPorro et al. 2014). Our results showed also the presence of the species Thermus, which is known to grow at elevated temperatures and it has often been inferred to biotechnology. Cells of Thermus can be used as factories for the recombinant production of thermophilic proteins at their natural temperatures, as well as, plasmids, thermostable enzymes (i.e., Taq polymerase), reporters, and promoters (Bergquist and Morgan 1995). Between the bacterial species that were detected in the tannery site and have promising biotechnological applications is Parasporobacterium sp. This type of bacteria is known to produce dimethyl sulfide and methanethiol from methoxycontaining aromatic compounds and sulfide (Whitman 2015). Deinococcus sp. is known to resist the damage caused by ionizing radiation, desiccation, UV radiation, and oxidizing agents. Additionally, they have the ability to degrade and metabolize sugars and polymeric sugars make them an attractive alternative for use in industrial biotechnology (Gerber et al. 2015).

\section{Conclusion}

The present study aimed to illustrate the impact of different doses of gamma radiation on contaminated soil samples collected from an old-fashioned tannery site using 454 pyrosequencing. This study provides information about potential "radioresistant" and/or "radiotolerant" microbial species that are adapted to elevated level of chemical toxicity such as $\mathrm{Cr}$ and $\mathrm{Sr}$ in tannery. These species can be of a high biotechnological and environmental importance. The redistribution of the indigenous microbial community as a result of gamma radiation might arise from the natural behavior or processes of the microbial community when exposed to external stress. The recovery of non-spore-forming and Gram-negative anaerobes after soil irradiation warrants further study and evaluation.

Acknowledgements The authors would like to thank King Abdulaziz City for Science and Technology (KACST) and its financial support is gratefully acknowledged. This work was funded through grant nos. 33874 and 33-375.

Funding information The study was funded by King Abdulaziz City for Science and Technology (KACST)/Saudi Arabia.

Compliance with ethical standards The work here was done in compliance of the ethical standards following for the environmental samples. There is no involvement of any animals or humans in this work.

Conflict of interest The authors declare that they have no conflict of interest.

Open Access This article is licensed under a Creative Commons Attribution 4.0 International License, which permits use, sharing, adaptation, distribution and reproduction in any medium or format, as long as you give appropriate credit to the original author(s) and the source, provide a link to the Creative Commons licence, and indicate if changes were made. The images or other third party material in this article are included in the article's Creative Commons licence, unless indicated otherwise in a credit line to the material. If material is not included in the article's Creative Commons licence and your intended use is not permitted by statutory regulation or exceeds the permitted use, you will need to obtain permission directly from the copyright holder. To view a copy of this licence, visit http://creativecommons.org/licenses/by/4.0/.

\section{References}

Albokari M, Arishi A, Essa A (2018) Molecular analysis of the bacterial communities from tannery contaminated sites in Riyadh. Saudi Arab Res J Biotechnol 13:3

Al-Najjar MAA, Ramette A, Kühl M, Hamza W, Klatt JM, Polerecky L (2014) Spatial patterns and links between microbial community composition and function in cyanobacterial mats. Front Microbiol 5. https://doi.org/10.3389/fmicb.2014.00406

Al-Thani R, Al-Najjar MAA, Al-Raei AM et al (2014) Community structure and activity of a highly dynamic and nutrient-limited hypersaline microbial mat in Um Alhool Sabkha, Qatar. PLoS One 9: e92405. https://doi.org/10.1371/journal.pone.0092405

Bergquist PL, Morgan HW (1995) Biotechnological applications of Thermus. In: Sharp R, Williams R (eds) Thermus species. Springer US, Boston, pp 207-227. https://doi.org/10.1007/978-14615-1831-0 8

Billi D, Friedmann EI, Hofer KG, Caiola MG, Ocampo-Friedmann R (2000) Ionizing-radiation resistance in the desiccation-tolerant cyanobacterium Chroococcidiopsis. Appl Environ Microbiol 66:14891492. https://doi.org/10.1128/AEM.66.4.1489-1492.2000

Brooks B, Murray R (1981) Nomenclature for "Micrococcus radiodurans" and other radiation-resistant cocci: Deinococcaceae fam. nov. and Deinococcus gen. nov., including five species. Int J Syst Evol Microbiol 31:353-360. https://doi.org/10.1099/ 00207713-31-3-353

Brown AR, Boothman C, Pimblott SM, Lloyd JR (2015) The impact of gamma radiation on sediment microbial processes. Appl Environ Microbiol 81:4014 4025. https://doi.org/10.1128/AEM.00590-15 
Caporaso JG, Lauber CL, Walters et al (2011) Global patterns of $16 \mathrm{~S}$ rRNA diversity at a depth of millions of sequences per sample. Proc Natl Acad Sci U S A 108:4516-4522. https://doi.org/10. 1073/pnas. 1000080107

Cha S, Srinivasan S, Seo T, Kim MK (2014) Deinococcus radiotolerans sp. nov., a gamma-radiation-resistant bacterium isolated from gamma ray-irradiated soil. Antonie Van Leeuwenhoek 105:229-235. https://doi.org/10.1007/s10482-013-0069-0

Chanal A, Chapon V, Benzerara K et al (2006) The desert of Tataouine: an extreme environment that hosts a wide diversity of microorganisms and radiotolerant bacteria. Environ Microbiol 8:514-525. https://doi.org/10.1111/j.1462-2920.2005.00921.x

Chen M-Y, Wu S-H, Lin G-H, Lu C-P, Lin Y-T, Chang W-C, Tsay S-S (2004) Rubrobacter taiwanensis sp. nov., a novel thermophilic, radiation-resistant species isolated from hot springs. Int J Syst Evol Microbiol 54:1849-1855. https://doi.org/10.1099/ijs.0.631090

Chennu A, Grinham A, Polerecky L, De Beer D, Al-Najjar MAA (2015) Rapid reactivation of cyanobacterial photosynthesis and migration upon rehydration of desiccated marine microbial mats. Front Microbiol 6. https://doi.org/10.3389/fmicb.2015.01472

Dahle H, Birkeland N-K (2006) Thermovirga lienii gen. nov., sp. nov., a novel moderately thermophilic, anaerobic, amino-acid-degrading bacterium isolated from a North Sea oil well. Int J Syst Evol Microbiol 56:1539-1545. https://doi.org/10.1099/ijs.0.63894-0

de Groot A, Chapon V, Servant P, Christen R, Saux MF-L, Sommer S, Heulin T (2005) Deinococcus deserti sp. nov., a gamma-radiationtolerant bacterium isolated from the Sahara Desert. Int J Syst Evol Microbiol 55:2441-2446. https://doi.org/10.1099/ijs.0.63717-0

Delmont TO, Robe P, Cecillon S et al (2011) Accessing the soil metagenome for studies of microbial diversity. Appl Environ Microbiol 77:1315-1324. https://doi.org/10.1128/aem.01526-10

Denger K, Warthmann R, Ludwig W, Schink B (2002) Anaerophaga thermohalophila gen. nov., sp. nov., a moderately thermohalophilic, strictly anaerobic fermentative bacterium. Int J Syst Evol Microbiol 52:173-178. https://doi.org/10.1099/00207713-52-1-173

DeSantis TZ, Hugenholtz P, Larsen N, Rojas M et al (2006) Greengenes, a chimera-checked 16S rRNA gene database and workbench compatible with ARB. Appl Environ Microbiol 72:5069-5072. https:// doi.org/10.1128/aem.03006-05

Dowd SE, Callaway TR, Wolcott RD, Sun Y, McKeehan T, Hagevoort RG, Edrington TS (2008a) Evaluation of the bacterial diversity in the feces of cattle using 16S rDNA bacterial tag-encoded FLX amplicon pyrosequencing (bTEFAP). BMC Microbiol 8:125. https://doi.org/10.1186/1471-2180-8-125

Dowd SE, Sun Y, Wolcott RD, Domingo A, Carroll JA (2008b) Bacterial tag-encoded FLX amplicon pyrosequencing (bTEFAP) for microbiome studies: bacterial diversity in the ileum of newly weaned Salmonella-infected pigs. Foodborne Pathog Dis 5(4): $459-472$

El-Sayed WS, Ghanem S (2009) Bacterial community structure change induced by gamma irradiation in hydrocarbon contaminated and uncontaminated soils revealed by PCR-denaturing gradient gel electrophoresis. Biotechnology 8:78-85. https://doi.org/10.3923/ biotech.2009.78.85

Eun SJ, Jae JL, Myung-Suk K et al (2016) Deinococcus actinosclerus sp. nov., a novel bacterium isolated from soil of a rocky hillside. Int $\mathrm{J}$ Syst Evol Microbiol 66:1003-1008. https://doi.org/10.1099/ijsem.0. 000825

Filippidou S, Junier T, Wunderlin T, Lo C-C, Li P-E, Chain PS, Junier P (2015) Under-detection of endospore-forming Firmicutes in metagenomic data. Comput Struct Biotechnol J 13:299-306. https://doi.org/10.1016/j.csbj.2015.04.002

Fredrickson JK, Zachara JM, Balkwill DL et al (2004) Geomicrobiology of high-level nuclear waste-contaminated vadose sediments at the
Hanford site, Washington state. Appl Environ Microbiol 70:4230 4241. https://doi.org/10.1128/aem.70.7.4230-4241.2004

Gabani P, Singh OV (2013) Radiation-resistant extremophiles and their potential in biotechnology and therapeutics. Appl Microbiol Biotechnol 97:993-1004. https://doi.org/10.1007/s00253-0124642-7

Gebremikael MT, De Waele J, Buchan D, Soboksa GE, De Neve S (2015) The effect of varying gamma irradiation doses and soil moisture content on nematodes, the microbial communities and mineral nitrogen. Appl Soil Ecol 92:1-13. https://doi.org/10.1016/j.apsoil. 2015.03.003

Gerber E, Bernard R, Castang S et al (2015) Deinococcus as new chassis for industrial biotechnology: biology, physiology and tools. J Appl Microbiol 119:1-10. https://doi.org/10.1111/jam.12808

Grabowski A, Tindall BJ, Bardin V, Blanchet D, Jeanthon C (2005) Petrimonas sulfuriphila gen. nov., sp. nov., a mesophilic fermentative bacterium isolated from a biodegraded oil reservoir. Int J Syst Evol Microbiol 55:1113-1121. https://doi.org/10.1099/ijs.0.63426-

Griffiths E, Gupta RS (2007) Identification of signature proteins that are distinctive of the Deinococcus-Thermus phylum. Int Microbiol 10: 203-208. https://doi.org/10.2436/20.1501.01.28

Hamady M, Lozupone C, Knight R (2009) Fast UniFrac: facilitating high-throughput phylogenetic analyses of microbial communities including analysis of pyrosequencing and PhyloChip data. ISME J 4:17. https://doi.org/10.1038/ismej.2009.97

Hamdi O, Hania WB, Postec A et al (2015) Aminobacterium thunnarium sp. nov., a mesophilic, amino acid-degrading bacterium isolated from an anaerobic sludge digester, pertaining to the phylum Synergistetes. Int J Syst Evol Microbiol 65:609-614. https://doi. org/10.1099/ijs.0.068965-0

Heng S, Sutheeworapong S, Prommeenate P et al (2019) Complete genome sequence of Halocella sp. Strain SP3-1, an extremely halophilic, glycoside hydrolase- and bacteriocin-producing bacterium isolated from a salt evaporation pond. Microbiol Resour Announc 8:e01696-e01618. https://doi.org/10.1128/mra.01696-18

Hirsch P, Gallikowski CA, Siebert J et al (2004) Deinococcus frigens sp. nov., Deinococcus saxicola sp. nov., and Deinococcus marmoris sp. nov., low temperature and draught-tolerating, UV-resistant bacteria from continental Antarctica. Syst Appl Microbiol 27:636-645. https://doi.org/10.1078/0723202042370008

Hollinshead WD, Varman AM, You L, Hembree Z, Tang YJ (2014) Boosting D-lactate production in engineered cyanobacteria using sterilized anaerobic digestion effluents. Bioresour Technol 169: 462-467. https://doi.org/10.1016/j.biortech.2014.07.003

Jeong H, Lim YW, Yi H, Sekiguchi Y, Kamagata Y, Chun J (2007) Anaerosporobacter mobilis gen. nov., sp. nov., isolated from forest soil. Int J Syst Evol Microbiol 57:1784-1787. https://doi.org/10. 1099/ijs.0.63283-0

Jiang H, Dong H, Zhang G, Yu B, Chapman LR, Fields MW (2006) Microbial diversity in water and sediment of Lake Chaka, an Athalassohaline Lake in northwestern China. Appl Environ Microbiol 72:3832-3845. https://doi.org/10.1128/aem.02869-05

Jolivet E, apos HS, Corre E, Forterre P, Prieur D (2003) Thermococcus gammatolerans sp. nov., a hyperthermophilic archaeon from a deepsea hydrothermal vent that resists ionizing radiation. Int J Syst Evol Microbiol 53:847-851. https://doi.org/10.1099/ijs.0.02503-0

Jolivet E, Corre E, L'Haridon S, Forterre P, Prieur D (2004) Thermococcus marinus sp. nov. and Thermococcus radiotolerans sp. nov., two hyperthermophilic archaea from deep-sea hydrothermal vents that resist ionizing radiation. Extremophiles 8:219-227. https://doi.org/10.1007/s00792-004-0380-9

Jumas-Bilak E, Roudière L, Marchandin H (2009) Description of 'Synergistetes' phyl. nov. and emended description of the phylum 'Deferribacteres' and of the family Syntrophomonadaceae, phylum 
'Firmicutes. Int J Syst Evol Microbiol 59:1028-1035. https://doi. org/10.1099/ijs.0.006718-0

Jung K-W, Lim S, Bahn Y-S (2017) Microbial radiation-resistance mechanisms. J Microbiol 55:499-507. https://doi.org/10.1007/s12275017-7242-5

Kabisch A, Otto A, König S et al (2014) Functional characterization of polysaccharide utilization loci in the marine Bacteroidetes 'Gramella forsetii’ KT0803. ISME J 8:1492. https://doi.org/10.1038/ismej. 2014.4

Kim K, Kim J-J, Masui R, Kuramitsu S, Sung M-H (2011) A commensal symbiotic interrelationship for the growth of Symbiobacterium toebii with its partner bacterium, Geobacillus toebii. BMC Res Notes 4:437. https://doi.org/10.1186/1756-0500-4-437

Lozupone CA, Hamady M, Kelley ST, Knight R (2007) Quantitative and qualitative $\beta$ diversity measures Lead to different insights into factors that structure microbial communities. Appl Environ Microbiol 73:1576-1585. https://doi.org/10.1128/aem.01996-06

McNamara NP, Black HIJ, Beresford NA, Parekh NR (2003) Effects of acute gamma irradiation on chemical, physical and biological properties of soils. Appl Soil Ecol 24:117-132. https://doi.org/10.1016/ S0929-1393(03)00073-8

Mechichi T, Labat M, Garcia J-L, Thomas P, Patel BKC (1999) Sporobacterium olearium gen. nov., sp. nov., a new methanethiolproducing bacterium that degrades aromatic compounds, isolated from an olive mill wastewater treatment digester. Int J Syst Evol Microbiol 49:1741-1748. https://doi.org/10.1099/00207713-49-41741

Nunan N, Leloup J, Ruamps LS, Pouteau V, Chenu C (2017) Effects of habitat constraints on soil microbial community function. Sci Rep 7: 4280. https://doi.org/10.1038/s41598-017-04485-z

Omelchenko MV, Wolf YI, Gaidamakova EK et al (2005) Comparative genomics of Thermus thermophilus and Deinococcus radiodurans: divergent routes of adaptation to thermophily and radiation resistance. BMC Evol Biol 5:57. https://doi.org/10.1186/1471-2148-5-57

Pavlopoulou A, Savva GD, Louka M, Bagos PG, Vorgias CE, Michalopoulos I, Georgakilas AG (2016) Unraveling the mechanisms of extreme radioresistance in prokaryotes: lessons from nature. Mutat Res Rev Mutat Res 767:92-107. https://doi.org/10. 1016/j.mrrev.2015.10.001

Phrommao E, Rodtong S, Yongsawatdigul J (2011) Identification of novel halotolerant bacillopeptidase F-like proteinases from a moderately halophilic bacterium, Virgibacillus sp. SK37. J Appl Microbiol 110: 191-201. https://doi.org/10.1111/j.1365-2672.2010.04871.x

Poehlein A, Gippert AL, Bierenbroodspot MJ, Daniel R (2017) First insights into the genome sequence of $<$ span class=" named-content genus-species" id="named-content-1" $>$ Clostridium oryzae $</$ span $>$ DSM 28571, isolated from the soil of a Japanese rice field. Genome Announc 5:e00539-e00517. https://doi.org/10.1128/ genomeA.00539-17

Rainey FA, Ray K, Ferreira M et al (2005) Extensive diversity of ionizing-radiation-resistant bacteria recovered from Sonoran Desert soil and description of nine new species of the genus Deinococcus obtained from a single soil sample. Appl Environ
Microbiol 71:5225-5235. https://doi.org/10.1128/aem.71.9.52255235.2005

Ranawat P, Rawat S (2017) Radiation resistance in thermophiles: mechanisms and applications. World J Microbiol Biotechnol 33:112. https://doi.org/10.1007/s11274-017-2279-5

Sánchez-Porro C, de la Haba RR, Ventosa A (2014) The genus Virgibacillus. In: Rosenberg E, DeLong EF, Lory S, Stackebrandt E, Thompson F (eds) The prokaryotes: Firmicutes and Tenericutes. Springer, Berlin, Heidelberg, pp 455-465. https://doi.org/10.1007/ 978-3-642-30120-9_353

Schaller J, Weiske A, Dudel EG (2011) Effects of gamma-sterilization on DOC, uranium and arsenic remobilization from organic and microbial rich stream sediments. Sci Total Environ 409:3211-3214. https://doi.org/10.1016/j.scitotenv.2011.05.014

Song JB, Kuai LP (2017) Effects of irradiation on microbial community structure in the Yangtze River and selection of representative microorganisms. IOP Conference Series: Earth and Environmental Science 51:012024. https://doi.org/10.1088/1742-6596/51/1/ 012024

Srinivasan S, Lim S, Lim J-H, Jung H-Y, Kim MK (2017) Deinococcus rubrus sp. nov., a bacterium isolated from Antarctic coastal sea water. J Microbiol Biotechnol 27:535-541. https://doi.org/10.4014/ jmb.1609.09002

Thomas F, Hehemann J-H, Rebuffet E, Czjzek M, Michel G (2011) Environmental and gut Bacteroidetes: the food connection. Front Microbiol 2. https://doi.org/10.3389/fmicb.2011.00093

Ueda K, Yamashita A, Ishikawa J et al (2004) Genome sequence of Symbiobacterium thermophilum, an uncultivable bacterium that depends on microbial commensalism. Nucleic Acids Res 32(16): 4937-4944. https://doi.org/10.1093/nar/gkh830

VanMensel D, Chaganti SR, Boudens R, Reid T, Ciborowski J, Weisener C (2017) Investigating the microbial degradation potential in oil sands fluid fine tailings using gamma irradiation: a metagenomic perspective. Microb Ecol 74:362-372. https://doi.org/10.1007/ s00248-017-0953-7

Whitman WB (2015) Bergey's manual of systematics of archaea and bacteria

Wunderlin T, Junier T, Roussel-Delif L, Jeanneret N, Junier P (2013) Stage 0 sporulation gene $\mathrm{A}$ as a molecular marker to study diversity of endospore-forming Firmicutes. Environ Microbiol Rep 5:911924. https://doi.org/10.1111/1758-2229.12094

Zhang Q, Liu C, Tang Y, Zhou G, Shen P, Fang C, Yokota A (2007) Hymenobacter xinjiangensis sp. nov., a radiation-resistant bacterium isolated from the desert of Xinjiang, China. Int J Syst Evol Microbiol 57:1752-1756. https://doi.org/10.1099/ijs.0.65033-0

Zhu J, Li SH, Tang QY et al (2017) Deinococcus malanensis sp. nov., isolated from radiation-polluted soil. Arch Microbiol 199:621-626. https://doi.org/10.1007/s00203-016-1335-0

Publisher's note Springer Nature remains neutral with regard to jurisdictional claims in published maps and institutional affiliations. 